\title{
What Do We Currently Know about the Pathophysiology of Alcoholic Pancreatitis: A Brief Review
}

\author{
Michał Żorniak ${ }^{a}$ b Simon Sirtl ${ }^{\mathrm{a}} \quad$ Julia Mayerle ${ }^{\mathrm{a}}$ Georg Beyer $^{\mathrm{a}}$ \\ ${ }^{a}$ Medical Department II, University Hospital, LMU Munich, Munich, Germany; \\ ${ }^{b}$ Department of Gastroenterology, Medical University of Silesia, Katowice, Poland
}

\section{Keywords}

Alcohol-related disease - Acute and chronic pancreatitis . Genetic factors in pancreatitis · Environmental factors in pancreatitis

\begin{abstract}
Background: Alcoholic pancreatitis is a serious medical concern worldwide and remains to be one of the common causes of pancreatic disease. Summary: While alcohol consumption causes direct damage to pancreatic tissue, only a small percentage of active drinkers will develop pancreatitis. An explanation of this phenomenon is probably that alcohol increases pancreatic vulnerability to damage; however, the simultaneous presence of additional risk factors and pancreatic costressors is required to increase the risk of pancreatitis and its complications caused by alcohol misuse. Recently, a number of important genetic as well as environmental factors influencing the risk of alcoholic pancreatitis have been described. Key Messages: In brief, this review reports established factors for the development of alcoholic pancreatitis and summarizes recent progress made in basic and clinical research.

(c) 2020 S. Karger AG, Basel
\end{abstract}

\section{Introduction}

Alcohol consumption is a major public health concern, and Europe has the highest levels of active drinkers in the world. According to the previously published Unit- ed European Gastroenterology Survey of Digestive Health across Europe, 155 billion EUR are spent every year as a result of alcohol misuse [1]. Alcohol drinking is also considered a well-established risk factor of acute and chronic pancreatitis contributing to between 50 and $80 \%$ of all cases (with regional differences in prevalence) [2]. Recently published validation studies on demographics, etiology, and risk factors for chronic pancreatitis reported by the North American Pancreas Study Group confirmed that alcohol remains the single most common etiology (46\%) of this disease in the USA [3].

On the other hand, less than $5 \%$ of heavy drinkers (defined by most authors as drinking of $\geq 4-5$ drinks on 5 or more days a month; a standard drink is approx. 8-14 g of pure alcohol - depending on country) will develop an episode of pancreatitis [4]. The underlying explanation of this phenomenon is that alcohol toxicity requires additional risk factors, either environmental or genetic, for disease to occur (Fig. 1) [5,6]. In addition, in animal models alcohol by itself does not cause pancreatitis but rather sensitizes the pancreas to damage caused by a number of other pancreatic costressors [7, 8].

Numerous publications shed some light onto the pathophysiology of alcoholic pancreatitis. However, in many important issues we still lack conclusive understanding. In this review we briefly discuss the current hypotheses and views on the pathophysiology of alcoholic pancreatitis. 


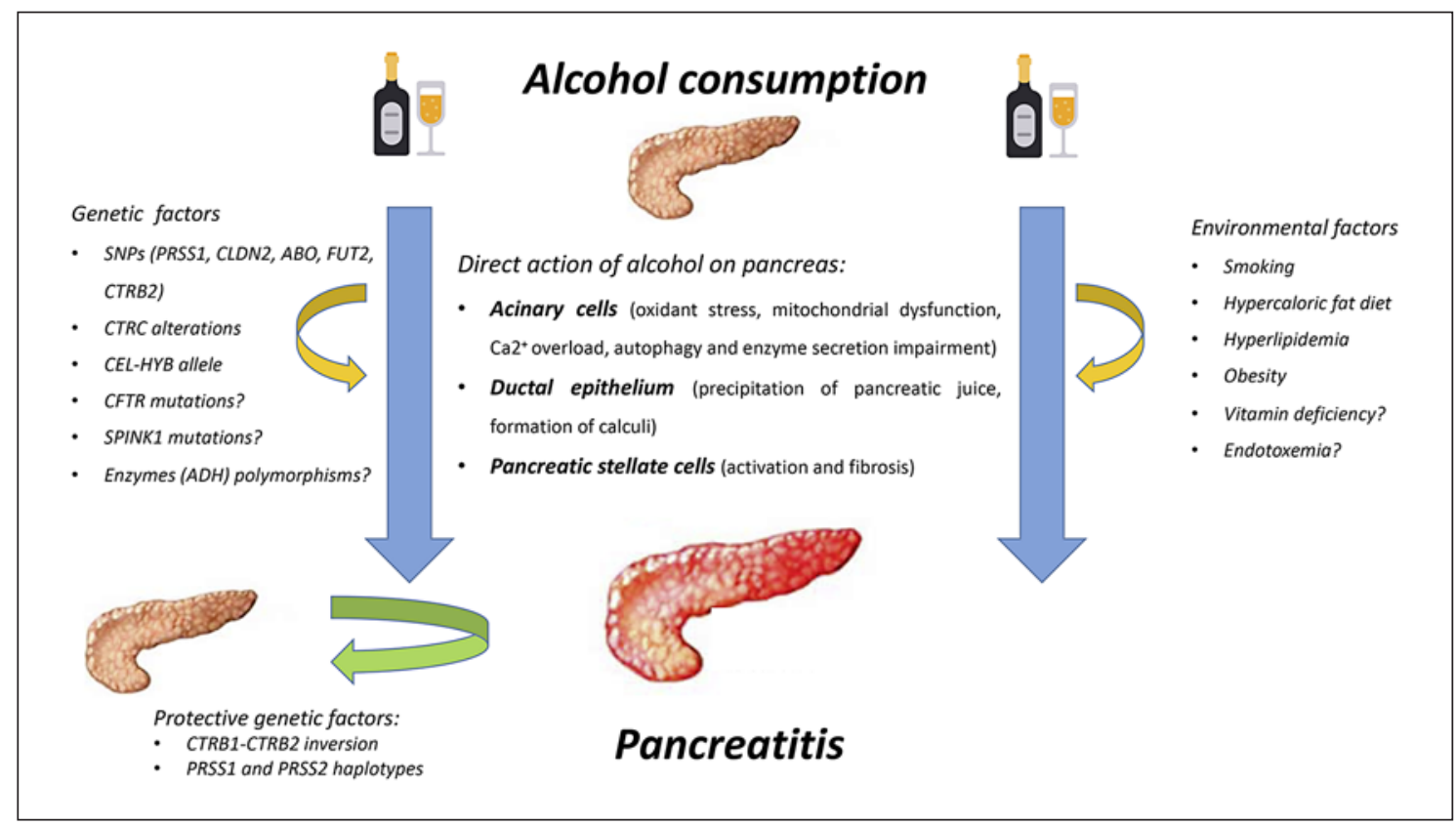

Fig. 1. Direct action of alcohol on the pancreas is caused by toxic influence on acinar, ductal, and stellate cells. Importantly, multiple genetic and environmental factors are involved and play a substantial role in developing alcoholic pancreatitis. Protective genetic variants decreasing the risk of disease have recently been described.

\section{Pathophysiology of Alcoholic Pancreatitis}

\section{The Influence of Alcohol on the Pancreas}

The pathophysiology of alcoholic pancreatitis remains incompletely understood as direct toxic actions exerted by alcohol on the pancreas are complex. It is assumed that alcohol damages acinar cells, pancreatic ductal epithelium and pancreatic stellate cells alike. Moreover, excessive alcohol consumption results in the creation of a proinflammatory microenvironment which promotes pancreatic fibrosis. It is important to understand that findings coming from animal models suggest that the pancreas can compensate harmful effects of alcohol through an adaptive stress response - such as the unfolded protein response (UPR; please see below) $[9,10]$. Alcoholic pancreatitis only occurs when compensatory mechanisms are exhausted or if increased vulnerability due to other (genetic and environmental) pancreatic costressors is present.

\section{Pancreatic Acinar Cells}

Pancreatic acinar cells metabolize alcohol via both oxidative and nonoxidative pathways (Fig. 2). Toxic effects of alcohol on acinar cells (autodigestive injury, necroinflammation, cell death) are partially due to its metabolism and generation of toxic components such as acetaldehyde, fatty acid ethyl esters (FAEEs), and reactive oxygen species [11]. Oxidative stress mediated by reactive oxygen species and FAEE leads to destabilization of zymogen granules and lysosomes and other dysregulations of the cell organelle [4].

Oxidative alcohol metabolism results in mitochondrial dysfunction which is a universal trigger of apoptosis and necrosis as mitochondria are responsible for a range of cellular functions critical in regulating cell survival [12]. Mitochondrial dysfunction occurs because of membrane permeabilization mediated by persistent opening of the mitochondrial permeability transition pore, resulting in loss of mitochondrial membrane potential and mitochondrial fragmentation. Mechanisms of mitochondrial permeability transition pore opening are a decrease in the ratio of nicotinamide adenine dinucleotide to nicotinamide adenine dinucleotide plus hydrogen resulting from oxidative alcohol metabolism [13].

Alcohol impacts on the endoplasmic reticulum (ER) network, whose function is crucial for protein folding and enzyme production in acinar cells $[9,14]$. Key factors maintaining ER homeostasis are $\mathrm{Ca}^{2+}$, ATP, and a controlled oxidative environment [10]. Enzyme secretion from acinar cells is mediated by oscillations of cytosolic $\mathrm{Ca}^{2+}$. Normally this is a transient event because of the reuptake of $\mathrm{Ca}^{2+}$ back into the cellular stores. Ethanol metabolites cause massive and persistent $\mathrm{Ca}^{2+}$ release from the ER $[15,16]$. This store depletion activates the $\mathrm{Ca}^{2+}$ influx, as acinar cells attempt to "refill" ER stores by the store-operated $\mathrm{Ca}^{2+}$ channel [17]. Its activation causes a considerable cytosolic $\mathrm{Ca}^{2+}$ increase which is a central event in promoting pathological events of pancreatitis 
Fig. 2. Direct action of alcohol on pancreatic acinar cells has varied pathways. Alcohol-related intracellular activation of proteases is caused by disruption of apical secretion as well as increased levels of circulating TNF- $\alpha$. Disturbed apical secretion of proteases also causes basolateral release of zymogen and its activation in interstitial space. Oxidative metabolism of alcohol leads to mitochondrial dysfunction and subsequent apoptosis. ER dysfunction caused by alcohol increases $\mathrm{Ca} 2^{+}$levels and leads to reduction of ATP production in pancreatic acinar cells and subsequently causes further ER damage.

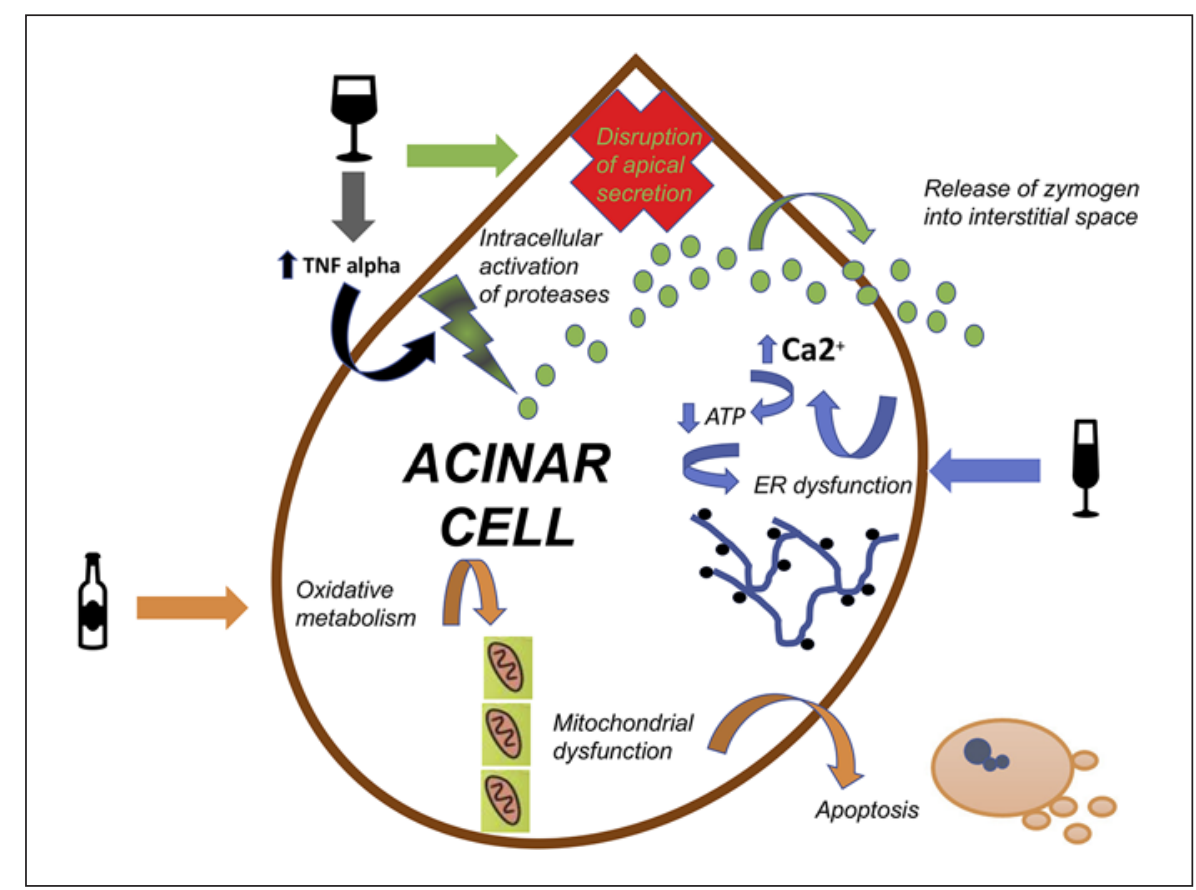

[18]. $\mathrm{Ca}^{2+}$ overload also greatly reduces ATP production in pancreatic acinar cells and subsequently causes further ER dysfunction [19].

In order to protect and adjust to changing demands encountered by the ER protein synthesis and processing machinery, eukaryotic cells have developed the UPR. The UPR is activated by accumulation of unfolded proteins in the ER lumen, a condition termed "ER stress" $[9,10]$. In response to chronic alcohol misuse and oxidative stress, this mechanism causes upregulation of spliced $\mathrm{X}$ boxbinding protein (sXBP1) which limits alcohol damage [9]. sXBP1 regulates a broad spectrum of UPR genes involved in protein folding $[10,20,21]$. The effects of sXBP1 generally adapt to ER stressors and enhance normal function in many cells but play an especially important supportive role in secretory cells. Interestingly, it was demonstrated that cigarette smoke reduces sXBP1 levels and inreases ER stress and cell death in acinar cells [22]. This could partially explain the mechanism due to which smoking becomes a risk factor for pancreatitis (acute, recurrent, and chronic) in addition to heavy alcohol abuse.

Impairment of autophagy is also a characteristic feature of alcoholic pancreatitis. Autophagy is a crucial pathway for degradation of organelles and proteins. It starts with sequestration of the material destined for degradation into autophagosomes, which then fuse with lysosomes forming autolysosomes in which cargo is degraded by lysosomal hydrolases [23]. Acinar cells with enlarged, abnormal autolysosomes containing poorly degraded cargo are a characteristic early sign of pancreatitis [24]. Levels of lysosome-associated membrane proteins, which are crucial for maintaining the function of lysosomes, are significantly decreased in experimental models of alcoholic pancreatitis $[25,26]$.

Another important mechanism affecting acinar cells and contributing to alcoholic pancreatitis is the disruption of apical secretion of zymogens. Under normal conditions pancreatic acinar cells are strictly polarized cells. This means that intracellular accumulated zymogen granules undergo exocytosis at the apex of the cell, emptying into the gut lumen digesting food [27]. A block of apical secretion causes activation of proteases within acinar cells, as well as basolateral exocytosis through the basolateral plasma membrane in the acinar cell releasing active zymogens into the interstitial space. This causes protease-induced injury to the cell membranes [28]. CosenBinker et al. [27] demonstrated that addition of alcohol to submaximal cholecystokinine stimulation of acinar cells mimics supramaximal cholecystokinine-induced apical blockade and redirects exocytosis to ectopic sites on the basolateral plasma membrane via protein kinase C-mediated activation of the Munc18c protein leading to pancreatitis. The authors postulated that this may be a crucial process involving acinar cell damage caused by alcohol [27]. High alcohol intake also increases levels of circulating TNF- $\alpha-a$ factor which directly induces premature protease activation and necrosis in pancreatic acinar cells [29].

\section{Pancreatic Ducts}

Ductal involvement in alcoholic pancreatitis is caused by changes of viscosity of pancreatic juice and enhancing its self-aggregation. Alcohol increases precipitation of pancreatic juice and formation of protein plugs inside 
Fig. 3. Influence of alcohol on pancreatic stellate cells (PSCs) causes production of acetylaldehyde (via oxidative metabolism pathway) and causes a significant increase in oxidative stress. Excessive alcohol intake increases also circulating levels of lipopolysaccharide (LPS) as well as TNF- $\alpha$ which activate PSCs and create a proinflammatory microenvironment which promotes pancreatic fibrosis.

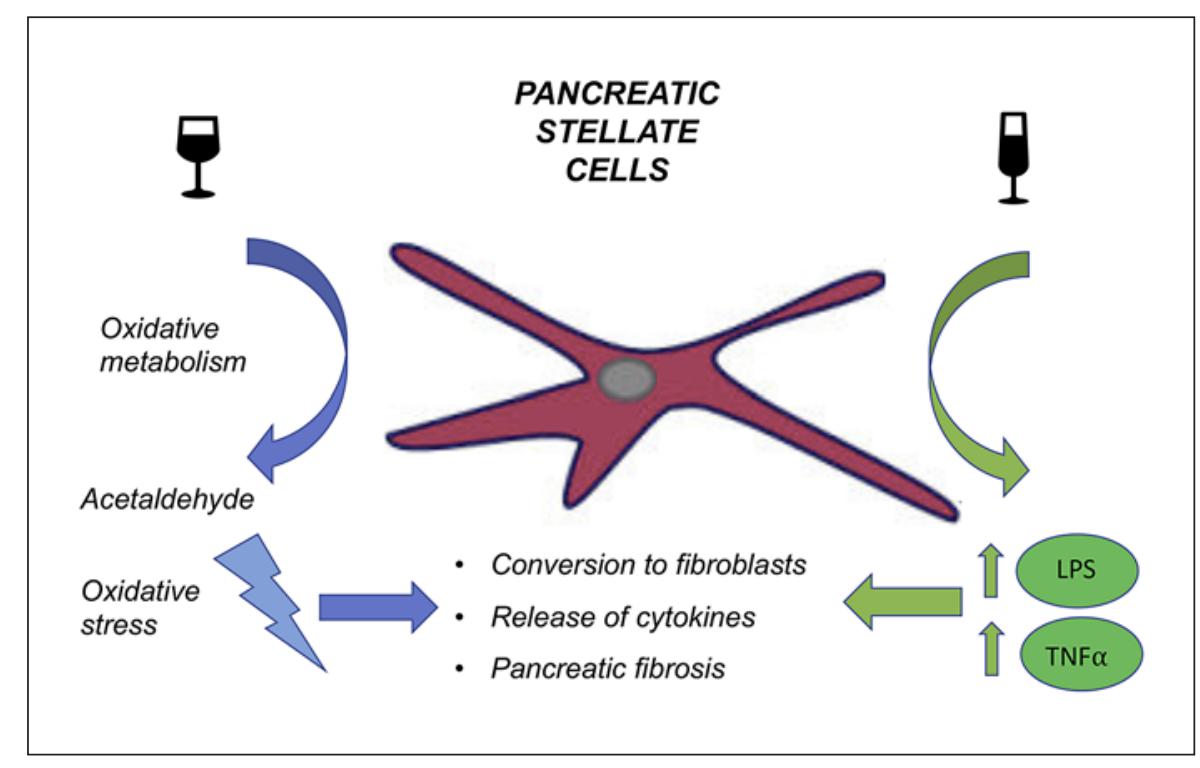

pancreatic ducts. Formation and enlargement of protein plugs results in formation of calculi which damage ductal epithelium and cause obstruction of pancreatic ducts [30]. The mechanism of this phenomenon is not clear. Apte et al. [31] have shown that long-term alcohol administration in rats causes a significant increase in lithostathine mRNA levels, which could in turn lead to increased concentrations of lithosthatine in pancreatic juice and promote protein deposition in pancreatic ducts. However, reports on the levels of lithostathine in the pancreatic fluids or tissue of patients with alcoholic pancreatitis are conflicting [32].

On the other hand, plug formation in alcoholic pancreatitis resembles pathologies found in cystic fibrosis which is caused by the loss of function of the exocrine pancreatic function caused by mutations in the cystic fibrosis transmembrane conductance regulator (CFTR) gene. CFTR levels are lower in pancreatic tissue from patients with chronic and acute pancreatitis - compared to healthy subjects [33]. These findings were confirmed in animal ductal cell models where CFTR activity is inhibited by alcohol, and this effect is mediated by sustained increases in cytosolic $\mathrm{Ca}^{2+}$, mitochondrial depolarization, and cellular ATP depletion [33].

\section{Pancreatic Stellate Cells}

Alcohol activates pancreatic stellate cells (PSCs) which are normal resident cells of the pancreas present in the periacinar space regulating matrix turnover and playing a role in tissue repair $[34,35]$. PSCs have the capacity to oxidize alcohol to acetaldehyde, which is associated with the generation of reactive oxygen species, leading to oxidative stress. Moreover, excessive alcohol intake increases circulating levels of lipopolysaccharide as well as circulating levels of oxidized low-density lipoprotein and TNF- $\alpha$. Each of those factors manifest distinct effects on PSC activation [7, 36, 37]. Alcohol abuse causes conversion of PSCs into myofibroblast-like cells which in turn activate the inflammatory response, stimulate release of cytokines and release excessive amounts of extracellular matrix proteins (Fig. 3) [34].

\section{Inflammatory Cells in Alcoholic Pancreatitis}

Alcohol consumption leads to conversion of PSCs into myofibroblasts in parallel to the generation of an inflammatory microenvironment driven by alternatively activated macrophages, type $2 \mathrm{~T}$-helper cells, and results in pancreatic fibrosis which is recognized as an essential histopathological feature of chronic pancreatitis [38]. In general, it could be assumed that the complex process of fibrogenesis in alcoholic chronic pancreatitis is initiated by the infiltration of the pancreatic tissue by macrophages and other inflammatory cells that are attracted by tissue damage and, in concert with myofibroblasts, stimulated to produce fibrogenic cytokines [39]. Necrosis and resorption of damaged cells by macrophages could be the initial event that induces fibrogenesis [39]. Next, macrophages produce TGF- $\beta$ and PDGF-B - factors which cause activation and proliferation of the resident pancreatic fibroblasts with subsequent induction of their transformation into myofibroblast-like cells [40, 41]. As it was shown, infiltration of other inflammatory cells, such as lymphocytes, is also present in alcoholic pancreatitis [39]. Various studies have shown that lymphocytes and granulocytes could also possibly play a role in fibrogenesis [39, 42]. However, the role of other cells (especially type $2 \mathrm{~T}$ helper lymphocytes) in alcoholic pancreatitis still needs to be elucidated. 


\section{Genetic Factors and Their Role in Alcoholic}

Pancreatitis

The impact of genetic factors is of key interest and will potentially guide future studies investigating the pathophysiology of alcoholic pancreatitis. There has been some progress made recently, regarding the role of genetics, although there is still an urgent need of broadening our knowledge [43].

In the past decade there have been two large studies dealing with the role of genetic factors in pancreatitis in a broad approach. The prospective North American Pancreatitis Study 2 conducted from 2000 to 2006 in 19 centers in the USA enrolled patients with recurrent acute or chronic pancreatitis which then were genotyped for 625,739 single nucleotide polymorphisms [44]. Genomewide association studies (GWASs) identified and replicated variants PRSS1-PRSS2 and CLDN2 [5]. The PRSS1 variant probably influences vulnerability for alcoholic pancreatitis by altering the expression of the primary trypsinogen gene. A recent study has shown that expression of the mutant form of human PRSS1 (PRSS1R122H) in transgenic mice causes more severe pancreatitis after ethanol feeding compared to control or PRSS1 gene carriers [45], thus experimentally supporting the theory of interaction between genetic and environmental risk factors. Moreover, alterations in the trypsinogen-degrading enzyme chymotrypsin C were identified (variants: p. R254W and p.K247_R254del) as they are more common in patients with alcoholic chronic pancreatitis [46].

The CLDN2 variant in patients suffering from chronic pancreatitis is associated with an atypical localization (along the basolateral membrane of acinar cells) of claudin-2. Claudin-2, a tight junction protein, is normally localized between duct cells and endocrine islets. The authors also suggested that this mislocalization partially explains the high frequency of alcohol-related pancreatitis in men compared to females as alleles of the CLDN2 genotype interact with alcohol consumption amplifying the risk (male hemizygous frequency was 0.26 while that of female homozygotes was 0.07 ). Importantly, results of the study above were confirmed in another large European cohort of 3,062 patients. In this paper it was also stated that single nucleotide polymorphisms at the PRSS1PRSS2 locus and at the CLDN2 locus are strongly associated with alcoholic pancreatitis [47]. Interestingly, GWASs have also identified haplotypes in the PRSS1 and PRSS2 gene with a protective effect - decreasing the risk of alcoholic chronic pancreatitis (odds ratio $=1.5$ ) $[5,48]$.

Promising data regarding the identification of genetic factors enhancing the risk of alcoholic pancreatitis come from a recent German GWAS which recognized single nucleotide polymorphisms within genes encoding the AB0 blood group-specifying transferases A/B (AB0), fucosyltransferase 2 and chymotrypsinogen-B2. Those were shown to be significantly associated with elevated lipase activity levels in asymptomatic subjects [49]. Importantly, a significant association was confirmed for fucosyltransferase 2 nonsecretor status and the AB0 blood type $B$ in patients with chronic pancreatitis of alcoholrelated origin. Moreover, we reported a 2.3-fold pancreatitis risk with blood type $\mathrm{B}$ over blood type 0 . Additional European GWAS studies identified a large inversion at the chymotrypsinogen $\mathrm{B} 1-\mathrm{B} 2$ locus which is related to a modest decrease in risk for chronic alcoholic pancreatitis, due to a protective increase in trypsinogen degradation [50].

There were also some efforts to recognize other genetic factors influencing the protease/antiprotease balance which could play a role in alcoholic pancreatitis, such as mutations in the serine protease inhibitor Kazal type 1 (SPINK1) gene. SPINK1 functions as a feedback inhibitor of activated trypsin and inhibiting prematurely activated trypsin [51]. However, although SPINK1 mutations are observed in individuals with chronic alcoholic pancreatitis, there is no evidence proving that they are more frequently found if compared to other subtypes of chronic pancreatitis $[52,53]$. The role of CFTR gene mutations in alcoholic pancreatitis remains controversial. Data coming from animal models have shown that CFTR knockout mice given ethanol developed more severe pancreatitis than control CFTR knockout mice [33]. In patients with chronic alcoholic pancreatitis an estimated $15 \%$ displayed a CFTR mutation [43]. This prevalence is comparable to the prevalence of CFTR mutations in other forms of chronic pancreatitis when the entire coding region of the CFTR gene is sequenced [54]. Moreover, so far almost all studies investigating the association of CFTR mutations with an increased risk of alcoholic pancreatitis showed a distribution comparable to that of the normal population $[55,56]$.

When it comes to genetic polymorphisms of alcoholmetabolizing enzymes taking part in oxidative and nonoxidative pathways, available data do not reveal unequivocal conclusions about their role in alcoholic pancreatitis. The nonoxidative pathway involves esterification of ethanol with fatty esters that result in the synthesis of FAEEs [57]. As it was mentioned before, FAEEs play an important role in the destabilization of acinar cells. After consumption of alcohol, accumulation of FAEEs in the pancreas is significantly higher compared to other organs [37]. It is partially driven by the activity of carboxylester lipase (CEL) which is responsible for synthesizing FAEEs. Limited data coming from a Japanese study on a male population of alcoholics suggested that the prevalence of long-type alleles is significantly higher in patients with alcoholic pancreatitis [58]. However, further studies in European cohorts did not confirm this association neither with alcoholic nor idiopathic pancreatitis $[59,60]$. 
On the other hand, Fjeld et al. [61] have recently described a hybrid allele (CEL-HYB) originating from a crossover between CEL and its neighboring pseudogene (CELP), which was significantly more common in a cohort of subjects with alcohol-related chronic pancreatitis (odds ratio $=2.3$ ).

As alcohol is mostly metabolized by alcohol-dehydrogenase and then by aldehyde-dehydrogenase, there is a number of studies regarding distribution of alleles encoding those enzymes; however, outcomes of studies are conflicting and indicate ethnic background as a strong confounder $[26,62,63]$.

\section{Environmental Factors and Their Role in Alcoholic \\ Pancreatitis}

Apart from direct toxic effects of alcohol and genetic susceptibility, smoking, obesity, dietary factors as well as bacteremia seem to play important roles in the development of alcoholic pancreatitis.

Smoking is generally accepted as an important risk factor of progression of pancreatitis [4]. Additionally, smokers also frequently drink more alcohol. Data coming from clinical observations show that tobacco intake accelerates the course of the disease in a dose-dependent fashion, apart from the amount of alcohol intake [64]. Results coming from a Japanese nationwide survey show that alcohol drinking as well as smoking are related to a higher incidence of complications in alcoholic pancreatitis [65]. A more recent meta-analysis of prospective studies suggests that tobacco smoking increases the risk of acute and chronic pancreatitis (the summary risk ratio was 1.49 and 1.93 , respectively) and that there is a dose-response relationship between increasing number of cigarettes and pancreatitis risk [66]. Moreover, the authors found that the associations between smoking and acute pancreatitis persisted among subgroups of studies that were adjusted for alcohol. However, the mechanisms of direct toxic effects caused by nicotine smoke inhalation are not clear. Although tobacco smoke contains more than 4,000 chemical compounds, experimental studies have mainly studied the role of nicotine and nicotine-derived substrates in relation to pancreatitis. It was suggested that smoking induces an inflammatory process in pancreatic tissue, as it stimulates expression of pancreatic procollagen 1 gene, interleukin- $1 ß$ and TGF- $\beta$ in acinar cells $[67,68]$. Moreover, it has been shown that cigarette smoking extract as well as nicotine and one of its major metabolites cause activation of PSCs via nicotinic acetylcholine receptors. This effect may contribute to activation of fibrosis and progression of chronic pancreatitis [69].

Hypercaloric-high-fat diet and obesity in the period of time before the onset of alcoholic pancreatitis are recognized as additional risk factors for disease development. It was well demonstrated that visceral fat necrosis wors- ens acute pancreatitis outcome in obese patients [70]. A recent study has shown that chronic pancreatitis is also associated with a higher visceral fat fraction - which is also present in central obesity and metabolic syndrome $[71,72]$. Moreover, a Swiss study found that obesity before the onset of chronic alcoholic pancreatitis was found to be significantly more frequent compared to the control population (15 vs 3.1\%) [73]. The mechanism underlying those observations could be partially explained by effects caused by degradation of lipids caused by lipolytic enzymes. Nagai et al. [74] have demonstrated in an in vitro model that interstitial release of degradation products from triglycerides by lipase and phospholipase causes cellular disruption. More recently, it has also been shown that during pancreatitis, pancreatic triglyceride lipase damages adipocytes and leads to the release of excessive nonesterified fatty acids, which are related to a worsened course of the disease [75].

Moreover, hyperlipidemia is a risk factor of both severe acute and chronic pancreatitis [76]. The nonoxidative pathway of ethanol metabolism generates FAEEs from fatty acid substrates via the action of carboxylester lipase secreted by the acinar cells [77, 78]. FAEEs induce sustained elevations of cytosolic $\mathrm{Ca}^{2+}$ and lead to inhibition of mitochondrial function, ATP loss and as a consequence death of the isolated acinar cell in an in vitro model [79]. Further FAEE hydrolysis which takes place in mitochondria leads to the release of free fatty acids and an increase in toxic effects [76]. Suggestions come from an in vitro model, confirmed in an in vivo animal study in which ethanol feeding exacerbated pancreatitis due to hyperlipidemia [80]. This is important in light of studies showing that humans dying from alcohol intoxication have high levels of FAEEs in the pancreas [81].

When it comes to other dietary factors which are suggested to contribute to the development of alcoholic pancreatitis, vitamin deficiency - common among severe alcoholics - is also disputed. So far data on this issue are scarce, and this matter needs further evaluation. There are single preliminary studies which deal with vitamin deficiency as a possible factor in disease onset. It has been well established that thiamine and folate deficiency occur in up to $80 \%$ of alcoholics $[82,83]$. Lately, Srinivasan et al. [84] found that chronic alcohol exposure significantly inhibited the uptake of thiamine pyrophosphate in pancreatic acinar cells in an animal model. The authors concluded that this effect of alcohol could have a negative effect on the physiological function of the mitochondria and as a consequence contribute to the development of alcoholic pancreatitis. Folate seems to be essential for pancreatic function as the pancreas maintains the second highest tissue level of folate after the liver and folate deficiency is related to disturbance of the exocrine function of this organ [85]. Another preliminary study revealed 
that chronic alcohol abuse causes a significant decrease in folate uptake by isolated rat pancreatic cells [86].

Recently, there has been a growing interest in bacterial endotoxemia as a possible factor triggering alcoholic pancreatitis. Serum levels of the bacterial cell wall component lipopolysaccharide are higher in individuals who abuse alcohol [28]. Alcohol is known to increase gut permeability; an inability to detoxify circulating endotoxins could make some drinkers susceptible to overt disease [4]. Data dealing with this issue are still lacking; however, there are some particularly interesting outcomes which come from animal experimental models. Vonlaufen et al. [87] had shown that endotoxin provocation leads to acute pancreatitis in alcohol-fed rats, whereas alcohol feeding alone did not cause any damage. Authors also noted significant stimulation of fibrosis which was due to a TLR4mediated effect on PSCs.

\section{Conclusion}

The direct link between alcohol abuse and pancreatic disease has long been recognized. It has been proven that alcohol misuse is one of the most frequent causes of acute and chronic pancreatitis. Surprisingly, it is also documented that the majority of alcohol abusers will not develop alcoholic pancreatitis. As alcohol seems to increase pancreatic vulnerability to damage, a simultaneous pres- ence of additional risk factors and pancreatic costressors may dramatically increase the risk of complications caused by alcohol misuse. Up to date, there are wellknown genetic and environmental factors which enhance this risk; however, there is no doubt that many new factors are yet to be described. As alcohol consumption seems to be a growing health care issue of the modern world, it could be presumed that we are in need of more data about alcohol-related pancreas damage.

\section{Disclosure Statement}

The authors have no conflicts of interest to declare.

\section{Funding Sources}

This work has been supported by: PePPP center of excellence MV ESF/14-BM-A55-0045/16; ESF MV V-630-S-150-2012/132/ 133; DFG-CRC 1321-P14; DFG BE 6395/1-1; Dr. Michal Zorniak has been funded by a United European Gastroenterology (UEG) Research Fellowship Grant.

\section{Author Contributions}

All authors have read and agreed to submission of the article in its current form. M.Z.: literature research. M.Z. and G.B.: drafting and writing. S.S. and J.M.: proof reading, critical discussion, and editing. M.Z.: figures.

\section{References}

1 Anderson P, Dalziel K, Davies E, et al. Survey of digestive health across Europe: final report. 2. The economic impact and burden of digestive disorders. United Eur Gastroenterol J. 2014;2:544-6.

2 Żorniak M, Beyer G, Mayerle J. Risk Stratification and Early Conservative Treatment of Acute Pancreatitis. Visc Med. 2019 Apr;35(2): 82-9.

3 Conwell DL, Banks PA, Sandhu BS, Sherman S, Al-Kaade S, Gardner TB, et al. Validation of Demographics, Etiology, and Risk Factors for Chronic Pancreatitis in the USA: A Report of the North American Pancreas Study (NAPS) Group. Dig Dis Sci. 2017 Aug;62(8): 2133-40.

4 Lankisch PG, Apte M, Banks PA. Acute pancreatitis. Lancet. 2015 Jul;386(9988):85-96.

5 Whitcomb DC, LaRusch J, Krasinskas AM, Klei L, Smith JP, Brand RE, et al; Alzheimer's Disease Genetics Consortium. Common genetic variants in the CLDN2 and PRSS1PRSS2 loci alter risk for alcohol-related and sporadic pancreatitis. Nat Genet. 2012 Dec; 44(12):1349-54.

6 Pandol SJ, Lugea A, Mareninova OA, Smoot D, Gorelick FS, Gukovskaya AS, et al. Investigating the pathobiology of alcoholic pancreatitis. Alcohol Clin Exp Res. 2011 May;35(5): 830-7.
7 Apte MV, Phillips PA, Fahmy RG, Darby SJ, Rodgers SC, McCaughan GW, et al. Does alcohol directly stimulate pancreatic fibrogenesis? Studies with rat pancreatic stellate cells. Gastroenterology. 2000 Apr;118(4): 780-94.

8 Pandol SJ, Periskic S, Gukovsky I, Zaninovic $\mathrm{V}$, Jung Y, Zong Y, et al. Ethanol diet increases the sensitivity of rats to pancreatitis induced by cholecystokinin octapeptide. Gastroenterology. 1999 Sep;117(3):706-16.

9 Lugea A, Tischler D, Nguyen J, Gong J, Gukovsky I, French SW, et al. Adaptive unfolded protein response attenuates alcohol-induced pancreatic damage. Gastroenterology. 2011 Mar;140(3):987-97.

10 Lugea A, Waldron RT, Pandol SJ. Pancreatic adaptive responses in alcohol abuse: role of the unfolded protein response. Pancreatology. 2015 Jul;15(4 Suppl):S1-5.

11 Apte MV, Wilson JS, Korsten MA, McCaughan GW, Haber PS, Pirola RC. Effects of ethanol and protein deficiency on pancreatic digestive and lysosomal enzymes. Gut. 1995 Feb;36(2):287-93.

12 Spinelli JB, Haigis MC. The multifaceted contributions of mitochondria to cellular metabolism. Nat Cell Biol. 2018 Jul;20(7):745-54.

13 Shalbueva N, Mareninova OA, Gerloff A, Yuan J, Waldron RT, Pandol SJ, et al. Effects of oxidative alcohol metabolism on the mitochondrial permeability transition pore and necrosis in a mouse model of alcoholic pancreatitis. Gastroenterology. 2013 Feb;144(2): 437-446.e6.

14 Pandol SJ, Gorelick FS, Gerloff A, Lugea A. Alcohol abuse, endoplasmic reticulum stress and pancreatitis. Dig Dis. 2010;28(6):776-82.

15 Mukherjee R, Criddle DN, Gukovskaya A, Pandol S, Petersen OH, Sutton R. Mitochondrial injury in pancreatitis. Cell Calcium. 2008 Jul;44(1):14-23.

16 Gerasimenko JV, Gerasimenko OV, Petersen $\mathrm{OH}$. The role of $\mathrm{Ca} 2+$ in the pathophysiology of pancreatitis. J Physiol. 2014 Jan;592(2): 269-80.

17 Parekh AB, Putney JW Jr. Store-operated calcium channels. Physiol Rev. 2005 Apr;85(2): 757-810.

18 Criddle DN, Gerasimenko JV, Baumgartner HK, Jaffar M, Voronina S, Sutton R, et al. Calcium signalling and pancreatic cell death: apoptosis or necrosis? Cell Death Differ. 2007 Jul;14(7):1285-94.

19 Criddle DN, Murphy J, Fistetto G, Barrow S, Tepikin AV, Neoptolemos JP, et al. Fatty acid ethyl esters cause pancreatic calcium toxicity via inositol trisphosphate receptors and loss of ATP synthesis. Gastroenterology. 2006 Mar;130(3):781-93. 
20 Kaser A, Lee AH, Franke A, Glickman JN, Zeissig S, Tilg H, et al. XBP1 links ER stress to intestinal inflammation and confers genetic risk for human inflammatory bowel disease. Cell. 2008 Sep;134(5):743-56.

21 Lee AH, Chu GC, Iwakoshi NN, Glimcher LH. XBP-1 is required for biogenesis of cellular secretory machinery of exocrine glands. EMBO J. 2005 Dec;24(24):4368-80.

22 Lugea A, Gerloff A, Su HY, Xu Z, Go A, Hu C, et al. The Combination of Alcohol and Cigarette Smoke Induces Endoplasmic Reticulum Stress and Cell Death in Pancreatic Acinar Cells. Gastroenterology. 2017 Dec;153(6): 1674-86.

23 Stolz A, Ernst A, Dikic I. Cargo recognition and trafficking in selective autophagy. Nat Cell Biol. 2014 Jun;16(6):495-501.

24 Yuan J, Liu Y, Tan T, Guha S, Gukovsky I, Gukovskaya A, et al. Protein kinase d regulates cell death pathways in experimental pancreatitis. Front Physiol. 2012 Mar;3:60.

25 Fortunato F, Bürgers H, Bergmann F, Rieger P, Büchler MW, Kroemer G, et al. Impaired autolysosome formation correlates with Lamp-2 depletion: role of apoptosis, autophagy, and necrosis in pancreatitis. Gastroenterology. 2009 Jul;137(1):350-60.

26 Mareninova OA, Sendler M, Malla SR, Yakubov I, French SW, Tokhtaeva E, et al. Lysosome associated membrane proteins maintain pancreatic acinar cell homeostasis: LAMP-2 deficient mice develop pancreatitis. Cell Mol Gastroenterol Hepatol. 2015 Nov; 1(6):678-94.

27 Cosen-Binker LI, Lam PP, Binker MG, Reeve J, Pandol S, Gaisano HY. Alcohol/cholecystokinin-evoked pancreatic acinar basolateral exocytosis is mediated by protein kinase $\mathrm{C} \mathrm{a}$ phosphorylation of Munc18c. J Biol Chem. 2007 Apr;282(17):13047-58.

28 Lerch MM, Gorelick FS. Models of acute and chronic pancreatitis. Gastroenterology. 2013 Jun; 144(6):1180-93.

29 Sendler M, Dummer A, Weiss FU, Krüger B, Wartmann T, Scharffetter-Kochanek K, et al. Tumour necrosis factor a secretion induces protease activation and acinar cell necrosis in acute experimental pancreatitis in mice. Gut. 2013 Mar;62(3):430-9.

30 Sarles H. Chronic calcifying pancreatitischronic alcoholic pancreatitis. Gastroenterology. 1974 Apr;66(4):604-16.

31 Apte MV, Norton ID, Haber PS, McCaughan GW, Korsten MA, Pirola RC, et al. Both ethanol and protein deficiency increase messenger RNA levels for pancreatic lithostathine. Life Sci. 1996;58(6):485-92.

32 Apte MV, Wilson JS, Korsten MA. Alcoholrelated pancreatic damage: mechanisms and treatment. Alcohol Health Res World. 1997; 21(1):13-20.

33 Maléth J, Balázs A, Pallagi P, Balla Z, Kui B, Katona M, et al. Alcohol disrupts levels and function of the cystic fibrosis transmembrane conductance regulator to promote development of pancreatitis. Gastroenterology. 2015 Feb;148(2):427-39.e16.

34 Apte MV, Pirola RC, Wilson JS. Mechanisms of alcoholic pancreatitis. J Gastroenterol Hepatol. 2010 Dec;25(12):1816-26.
35 Apte MV, Haber PS, Darby SJ, Rodgers SC, McCaughan GW, Korsten MA, et al. Pancreatic stellate cells are activated by proinflammatory cytokines: implications for pancreatic fibrogenesis. Gut. 1999 Apr;44(4):534-41.

36 Alho H, Sillanaukee P, Kalela A, Jaakkola O, Laine S, Nikkari ST. Alcohol misuse increases serum antibodies to oxidized LDL and C-reactive protein. Alcohol Alcohol. 2004 JulAug;39(4):312-5.

37 Gonzalez-Quintela A, Campos J, Loidi L, Quinteiro C, Perez LF, Gude F. Serum TNFalpha levels in relation to alcohol consumption and common TNF gene polymorphisms. Alcohol. 2008 Sep;42(6):513-8.

38 Xue J, Sharma V, Hsieh MH, Chawla A, Murali R, Pandol SJ, et al. Alternatively activated macrophages promote pancreatic fibrosis in chronic pancreatitis. Nat Commun. 2015 May;6(1):7158.

39 Detlefsen S, Sipos B, Feyerabend B, Klöppel G. Fibrogenesis in alcoholic chronic pancreatitis: the role of tissue necrosis, macrophages, myofibroblasts and cytokines. Mod Pathol. 2006 Aug;19(8):1019-26.

40 Shek FW, Benyon RC, Walker FM, McCrudden PR, Pender SL, Williams EJ, et al. Expression of transforming growth factor- $\beta 1$ by pancreatic stellate cells and its implications for matrix secretion and turnover in chronic pancreatitis. Am J Pathol. 2002 May;160(5): 1787-98.

41 Haber PS, Keogh GW, Apte MV, Moran CS, Stewart NL, Crawford DH, et al. Activation of pancreatic stellate cells in human and experimental pancreatic fibrosis. Am J Pathol. 1999 Oct;155(4):1087-95.

42 Ebert M, Kasper HU, Hernberg S, Friess H, Büchler MW, Roessner A, et al. Overexpression of platelet-derived growth factor (PDGF) $B$ chain and type $\beta$ PDGF receptor in human chronic pancreatitis. Dig Dis Sci. 1998 Mar; 43(3):567-74.

43 Aghdassi AA, Weiss FU, Mayerle J, Lerch MM, Simon P. Genetic susceptibility factors for alcohol-induced chronic pancreatitis. Pancreatology. 2015 Jul;15(4 Suppl):S23-31.

44 Whitcomb DC, Yadav D, Adam S, Hawes RH, Brand RE, Anderson MA, et al.; North American Pancreatic Study Group. Multicenter approach to recurrent acute and chronic pancreatitis in the United States: the North American Pancreatitis Study 2 (NAPS2). Pancreatology. 2008;8(4-5):520-31.

45 Huang H, Swidnicka-Siergiejko AK, Daniluk $\mathrm{J}$, et al. Transgenic expression of PRSS1R122H sensitizes mice to pancreatitis. Gastroenterology. 2019 Aug;pii:S0016-5085(19)41228-6.

46 Rosendahl J, Witt H, Szmola R, Bhatia E, Ozsvári $\mathrm{B}$, Landt $\mathrm{O}$, et al. Chymotrypsin $\mathrm{C}$ (CTRC) variants that diminish activity or secretion are associated with chronic pancreatitis. Nat Genet. 2008 Jan;40(1):78-82.

47 Derikx MH, Kovacs P, Scholz M, Masson E, Chen JM, Ruffert C, et al.; PanEuropean Working group on Alcoholic Chronic Pancreatitis Members and Collaborators. Polymorphisms at PRSS1-PRSS2 and CLDN2MORC4 loci associate with alcoholic and non-alcoholic chronic pancreatitis in a European replication study. Gut. 2015 Sep;64(9): 1426-33.
48 Witt H, Sahin-Tóth M, Landt O, Chen JM, Kähne T, Drenth JP, et al. A degradation-sensitive anionic trypsinogen (PRSS2) variant protects against chronic pancreatitis. Nat Genet. 2006 Jun;38(6):668-73.

49 Weiss FU, Schurmann C, Guenther A, Ernst F, Teumer A, Mayerle J, et al. Fucosyltransferase 2 (FUT2) non-secretor status and blood group B are associated with elevated serum lipase activity in asymptomatic subjects, and an increased risk for chronic pancreatitis: a genetic association study. Gut. 2015 Apr; 64(4):646-56.

50 Rosendahl J, Kirsten H, Hegyi E, Kovacs P, Weiss FU, Laumen $\mathrm{H}$, et al.; all members of the PanEuropean Working group on ACP. Genome-wide association study identifies inversion in the CTRB1-CTRB2 locus to modify risk for alcoholic and non-alcoholic chronic pancreatitis. Gut. 2018 Oct;67(10):185563.

51 Weiss FU, Simon P, Witt H, Mayerle J, Hlouschek V, Zimmer KP, et al. SPINK1 mutations and phenotypic expression in patients with pancreatitis associated with trypsinogen mutations. J Med Genet. 2003 Apr;40(4):e40.

52 Drenth JP, te Morsche R, Jansen JB. Mutations in serine protease inhibitor Kazal type 1 are strongly associated with chronic pancreatitis. Gut. 2002 May;50(5):687-92.

53 Schneider A, Pfützer RH, Barmada MM, Slivka A, Martin J, Whitcomb DC. Limited contribution of the SPINK1 N34S mutation to the risk and severity of alcoholic chronic pancreatitis: a report from the United States. Dig Dis Sci. 2003 Jun;48(6):1110-5.

54 Weiss FU, Simon P, Bogdanova N, Mayerle J, Dworniczak B, Horst J, et al. Complete cystic fibrosis transmembrane conductance regulator gene sequencing in patients with idiopathic chronic pancreatitis and controls. Gut. 2005 Oct;54(10):1456-60.

55 Witt H. Chronic pancreatitis and cystic fibrosis. Gut. 2003 May;52(90002 Suppl 2):ii31-41.

56 da Costa MZ, Guarita DR, Ono-Nita SK, Paranaguá-Vezozzo DC, Felga GE, Pedroso MR, et al. Genetic risk for alcoholic chronic pancreatitis. Int J Environ Res Public Health. $2011 \mathrm{Jul} ; 8(7): 2747-57$.

57 Wilson JS, Apte MV. Role of alcohol metabolism in alcoholic pancreatitis. Pancreas. 2003 Nov;27(4):311-5.

58 Miyasaka K, Ohta M, Takano S, Hayashi H, Higuchi S, Maruyama K, et al. Carboxylester lipase gene polymorphism as a risk of alcoholinduced pancreatitis. Pancreas. 2005 May; 30(4):e87-91.

59 Fjeld K, Beer S, Johnstone M, Zimmer C, Mössner J, Ruffert C, et al. Length of Variable Numbers of Tandem Repeats in the Carboxyl Ester Lipase (CEL) Gene May Confer Susceptibility to Alcoholic Liver Cirrhosis but Not Alcoholic Chronic Pancreatitis. PLoS One. 2016 Nov;11(11):e0165567

60 Ragvin A, Fjeld K, Weiss FU, Torsvik J, Aghdassi A, Mayerle J, et al. The number of tandem repeats in the carboxyl-ester lipase (CEL) gene as a risk factor in alcoholic and idiopathic chronic pancreatitis. Pancreatology. 2013 Jan-Feb;13(1):29-32. 
61 Fjeld K, Weiss FU, Lasher D, Rosendahl J, Chen JM, Johansson BB, et al. A recombined allele of the lipase gene CEL and its pseudogene CELP confers susceptibility to chronic pancreatitis. Nat Genet. 2015 May;47(5):51822.

62 Cichoz-Lach H, Partycka J, Nesina I, Celinski K, Slomka M, Wojcierowski J. Alcohol dehydrogenase and aldehyde dehydrogenase gene polymorphism in alcohol liver cirrhosis and alcohol chronic pancreatitis among Polish individuals. Scand J Gastroenterol. 2007 Apr; 42(4):493-8.

63 Agarwal DP. Genetic polymorphisms of alcohol metabolizing enzymes. Pathol Biol (Paris). 2001 Nov;49(9):703-9.

64 Rebours V, Vullierme MP, Hentic O, Maire F, Hammel P, Ruszniewski P, et al. Smoking and the course of recurrent acute and chronic alcoholic pancreatitis: a dose-dependent relationship. Pancreas. 2012 Nov;41(8):1219-24.

65 Hirota M, Shimosegawa T, Masamune A, Kikuta K, Kume K, Hamada S, et al.; Research Committee of Intractable Pancreatic Diseases. The seventh nationwide epidemiological survey for chronic pancreatitis in Japan: clinical significance of smoking habit in Japanese patients. Pancreatology. 2014 Nov-Dec;14(6): 490-6.

66 Aune D, Mahamat-Saleh Y, Norat T, Riboli E. Tobacco smoking and the risk of pancreatitis: A systematic review and meta-analysis of prospective studies. Pancreatology. 2019 Dec; 19(8):1009-22.

67 Prokopczyk B, Hoffmann D, Bologna M, Cunningham AJ, Trushin N, Akerkar S, et al. Identification of tobacco-derived compounds in human pancreatic juice. Chem Res Toxicol. 2002 May; 15(5):677-85.

68 Wittel UA, Pandey KK, Andrianifahanana M, Johansson SL, Cullen DM, Akhter MP, et al. Chronic pancreatic inflammation induced by environmental tobacco smoke inhalation in rats. Am J Gastroenterol. 2006 Jan;101(1): 148-59.
69 Lee ATK, Xu Z, Pothula SP, et al. Alcohol and cigarette smoke components activate human pancreatic stellate cells: implications for the progression of chronic pancreatitis. Alcohol Clin Exp Res. 2015;39:2123-33.

70 Navina S, Acharya C, DeLany JP, Orlichenko LS, Baty CJ, Shiva SS, et al. Lipotoxicity causes multisystem organ failure and exacerbates acute pancreatitis in obesity. Sci Transl Med. 2011 Nov;3(107):107ra110.

71 Poonawalla AH, Sjoberg BP, Rehm JL, Hernando D, Hines CD, Irarrazaval P, et al. Adipose tissue MRI for quantitative measurement of central obesity. J Magn Reson Imaging. 2013 Mar;37(3):707-16.

72 Bergman RN, Kim SP, Catalano KJ, Hsu IR, Chiu JD, Kabir M, et al. Why visceral fat is bad: mechanisms of the metabolic syndrome. Obesity (Silver Spring). 2006 Feb;14(2S Suppl 1):16S-9S.

73 Ammann RW, Raimondi S, Maisonneuve P, Mullhaupt B; Zurich Pancreatitis Study Group. Is obesity an additional risk factor for alcoholic chronic pancreatitis? Pancreatology. 2010;10(1):47-53.

74 Nagai H, Henrich H, Wünsch PH, Fischbach W, Mössner J. Role of pancreatic enzymes and their substrates in autodigestion of the pancreas. In vitro studies with isolated rat pancreatic acini. Gastroenterology. 1989 Mar;96(3): 838-47.

75 de Oliveira C, Khatua B, Noel P, Kostenko S, Bag A, Balakrishnan B, et al. Pancreatic triglyceride lipase mediates lipotoxic systemic inflammation. J Clin Invest. 2020 Apr;130(4): 1931-47.

76 Criddle DN. The role of fat and alcohol in acute pancreatitis: A dangerous liaison. Pancreatology. 2015 Jul;15(4 Suppl):S6-12.

77 Best CA, Laposata M. Fatty acid ethyl esters: toxic non-oxidative metabolites of ethanol and markers of ethanol intake. Front Biosci. 2003 Jan;8(5):e202-17.

78 Kannius-Janson M, Lidberg U, Bjursell G, Nilsson J. The tissue-specific regulation of the carboxyl ester lipase gene in exocrine pancreas differs significantly between mouse and human. Biochem J. 2000 Oct;351(Pt 2):36776
79 Criddle DN, Raraty MG, Neoptolemos JP, Tepikin AV, Petersen OH, Sutton R. Ethanol toxicity in pancreatic acinar cells: mediation by nonoxidative fatty acid metabolites. Proc Natl Acad Sci USA. 2004 Jul;101(29):1073843.

80 Grauvogel J, Daemmrich TD, Ryschich E, Gebhard MM, Werner J. Chronic alcohol intake increases the severity of pancreatitis induced by acute alcohol administration, hyperlipidemia and pancreatic duct obstruction in rats. Pancreatology. 2010;10(5):603-12.

81 Laposata EA, Lange LG. Presence of nonoxidative ethanol metabolism in human organs commonly damaged by ethanol abuse. Science. 1986 Jan;231(4737):497-9.

82 Martin PR, Singleton CK, Hiller-Sturmhöfel $\mathrm{S}$. The role of thiamine deficiency in alcoholic brain disease. Alcohol Res Health. 2003;27(2): 134-42.

83 Medici V, Halsted CH. Folate, alcohol, and liver disease. Mol Nutr Food Res. 2013 Apr; 57(4):596-606.

84 Srinivasan P, Nabokina S, Said HM. Chronic alcohol exposure affects pancreatic acinar mitochondrial thiamin pyrophosphate uptake: studies with mouse 266-6 cell line and primary cells. Am J Physiol Gastrointest Liver Physiol. 2015 Nov;309(9):G750-8.

85 Balaghi M, Horne DW, Woodward SC, Wagner C. Pancreatic one-carbon metabolism in early folate deficiency in rats. Am J Clin Nutr. 1993 Aug;58(2):198-203.

86 Said HM, Mee L, Sekar VT, Ashokkumar B, Pandol SJ. Mechanism and regulation of folate uptake by pancreatic acinar cells: effect of chronic alcohol consumption. Am J Physiol Gastrointest Liver Physiol. 2010 Jun; 298(6):G985-93.

87 Vonlaufen A, Xu Z, Daniel B, Kumar RK, Pirola $\mathrm{R}$, Wilson J, et al. Bacterial endotoxin: a trigger factor for alcoholic pancreatitis? Evidence from a novel, physiologically relevant animal model. Gastroenterology. 2007 Oct; 133(4):1293-303. 